«Системні технології» 4 (129) 2020 «System technologies»

DOI 10.34185/1562-9945-4-129-2020-02

УДК629.7.036

С.С. Василів, М.В. Євсєєнко

\title{
ВИКОРИСТАННЯ ДЕТОНАЦЙНОГО ПРОЦЕСУ ДЛЯ ПІДВИЩЕННЯ ЕНЕРГЕТИЧНИХ ХАРАКТЕРИСТИК РАКЕТНИХ ДВИГУНІВ ВЕРХНІХ СТУПЕНІВ, ПОБУДОВАНИХ ЗА ВІДКРИТОЮ СХЕМОЮ
}

Анотація. Стаття присвячена аналізу ефективності використання відпрацьованого на турбіні генераторного газу в двигунах верхніх ступенів ракет, що побудовані за відкритою схемою. Роботи над створенням ракетних двигунів, які використовують детонаційний процес згорання палива в камері, ведуться в різних країнах вже тривалий час. Основною причиною пошуків у цьому напрямку є вищий термодинамічний коефіцієнт корисної дії детонації в порівнянні з дефлаграцією. Також привабливою є перспектива відмови від турбонасосного агрегату при використанні простої витискувальної системи подачі, оскільки детонаційний процес може відбуватися при відносно низьких значеннях тисків компонентів палива.

Розглянуто варіанти вихлопу відпрацьованого турбінного генераторного газу в окреме сопло, допалювання його в дефлаграційному та детонаційному режимах. Визначено основні параметри двигунних установок з використанням цих пристроїв, порівняно їх з існуючим варіантом двигуна. Виявлено, що допалювання відпрацьованого на турбіні генераторного газу в детонаційному режимі дозволяє підвищити енергетичні характеристики ракетного двигуна побудованого за відкритою схемою та збільшити масу корисного вантажу, що виводиться на орбіту.

Ключеві слова: ракетний двигун, детонація, дефлаграція, генераторний газ.

Вступ. Покращення енергомасових характеристик ракетного двигуна верхнього ступеню є важливою задачею. Кожен зекономлений кілограм палива чи маси самого двигуна - це додатковий корисний вантаж. Зваживши на тенденції вдосконалення електронної апаратури космічних апаратів та зменшення її маси можна припустити, що покращення енергетичних можливостей верхнього ступеню ракети призведе до збільшення фінансової ефективності ракетного комплексу зокрема. Однак ресур-

(C) Василів С.С., Євсєєнко М.В., 2020 
«Системні технології» 4 (129) 2020 «System technologies»

си модернізації сучасних двигунів вже досить вичерпані. Це передусім викликано досягненням границі міцнісних характеристик конструкційних матеріалів та оптимізацією газодинамічних параметрів в камерах згорання. Останнє десятиліття проводяться експериментальні дослідження 3 метою виявлення можливостей використання детонаційних процесів замість горіння в камерах ракетних двигунів. Теоретично це дозволить збільшити питомий імпульс на 20-30\%. Це особливо актуально для двигунів верхніх ступенів, де необхідні високі енергомасові характеристики. Для цих установок характерне досить високе значення питомої маси, адже чим менша тяга, тим менша масова досконалість і важче двигун. Таку закономірність для двигунів других і третіх ступенів ракет можна побачити, проаналізувавши дані з таблиці 1[1]. Графік залежності питомої маси від тяги проілюстровано на рис.1

Таблиця 1

Характеристики двигунів верхніх ступенів ракет

\begin{tabular}{|c|c|c|c|c|c|c|c|}
\hline \multirow[b]{2}{*}{ Двигун } & \multicolumn{7}{|c|}{ Параметр } \\
\hline & 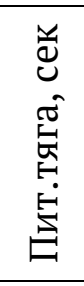 & 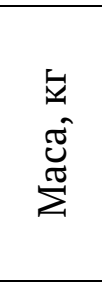 & 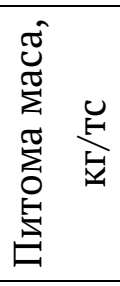 & 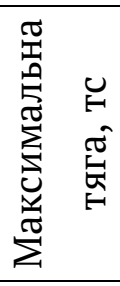 & 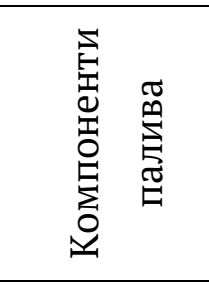 & 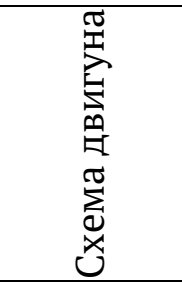 & 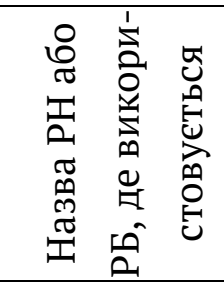 \\
\hline РД0124 & 59 & 460 & 15,33 & 30 & О2+гас & Закрита & Союз-2 \\
\hline РД0208 & 326 & 540 & 9,22 & 58,6 & АТ+НДМГ & Закрита & Протон \\
\hline 11Д114 & 353 & 722 & 17,4 & 41,5 & О2+гас & Закрита & $\mathrm{H}-1$ \\
\hline 11Д112 & 346 & 1396 & 7,8 & 179 & О2+гас & Закрита & $\mathrm{H}-1$ \\
\hline РД119 & 352 & 168 & 15,68 & 10,71 & О2+ НДМГ & Відкрита & Космос-1 \\
\hline РД120 & 350 & 1125 & 13,23 & 85 & О2+гас & Закрита & Зеніт-2,3 \\
\hline РД161 & 360 & 119 & 59,5 & 2 & О2+гас & Закрита & Союз \\
\hline РД219 & 293 & 665 & 7,39 & 89,95 & $\begin{array}{l}\text { АК27И+ } \\
\text { НДМГ }\end{array}$ & Відкрита & $8 \mathrm{~K} 64$ \\
\hline РД212 & 327 & 550 & 11,2 & 49,1 & АТ+НДМГ & Закрита & Протон \\
\hline РД252 & 317 & 720 & 7,5 & 95,9 & АТ+НДМГ & Відкрита & $8 \mathrm{~K} 67$ \\
\hline РД861К & 330 & 207 & 26,15 & 7,916 & АТ+НДМГ & Відкрита & Циклон-4М \\
\hline 15Д12 & 329 & 190 & 13,57 & 14 & АТ+НДМГ & Закрита & 8 K99 \\
\hline
\end{tabular}


«Системні технологіï» 4 (129) 2020 «System technologies»

\begin{tabular}{|l|l|l|l|l|l|l|l|}
\hline 15Д169 & 331 & 192 & 13,2 & 14,54 & АТ+НДМГ & Закрита & 15А15 \\
\hline $\begin{array}{l}\text { Merlin 1C } \\
\text { Vacuum }\end{array}$ & 342 & 450 & 10,7 & 42 & О2+гас & Відкрита & Falcon-9 \\
\hline $\begin{array}{l}\text { Merlin 1D } \\
\text { Vacuum+ }\end{array}$ & 347 & 490 & 5,14 & 95,3 & О2+гас & Відкрита & Falcon Heavy \\
\hline RL10C-1 & 450 & 190 & 18,3 & 10,38 & О2+ Н2 & Закрита & Centaur SEC \\
\hline Viking -4B & 301 & 826 & 10,06 & 82,09 & АТ+НДМГ & Відкрита & Ariane-4 \\
\hline Aestus 2 & 324 & 111 & 36,75 & 3,02 & АТ+НДМГ & Відкрита & Ariane-5 \\
\hline LE-5B-2 & 447 & 290 & 19,62 & 14,78 & О2+ Н2 & Закрита & Н-IIВ \\
\hline
\end{tabular}

Питома маса показує яка маса двигуна необхідна для створення 1 тони сили [2]. Звісно на цей параметр впливає не тільки масова досконалість установки, а й ефективність термодинамічного процесу. В свою чергу ця ефективність випливає зі схеми двигуна, компонентів палива та тиску в камері.

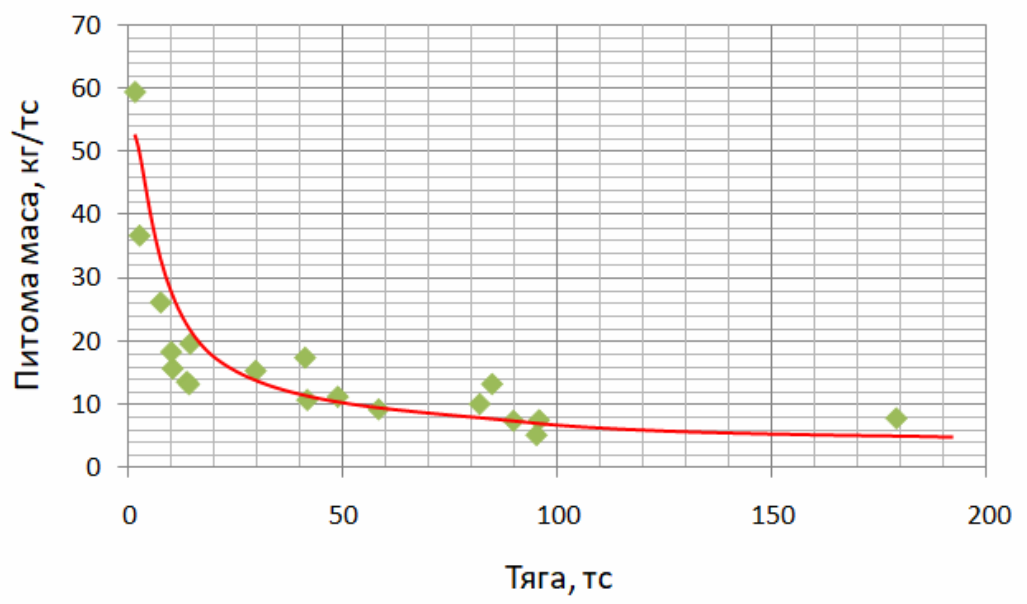

Рисунок 1 - Залежність питомої маси двигунів від тяги

Детонаційний режим реакції паливної суміші більш ефективний 3 термодинамічної точки зору. Тому його застосування може покращити енергетичні характеристики двигунів верхніх ступенів.

Метою роботи є оцінка ефективності допалювання відпрацьованого на турбіні генераторного газу в додатковій камері згорання в різних режимах. 
«Системні технології» 4 (129) 2020 «System technologies»

Для ракети Циклон-4M Державне підприємство «КБ Південне» буде використовувати двигун РД861К (рис.2), який був розроблений в рамках проекту «Циклон-4»[3].

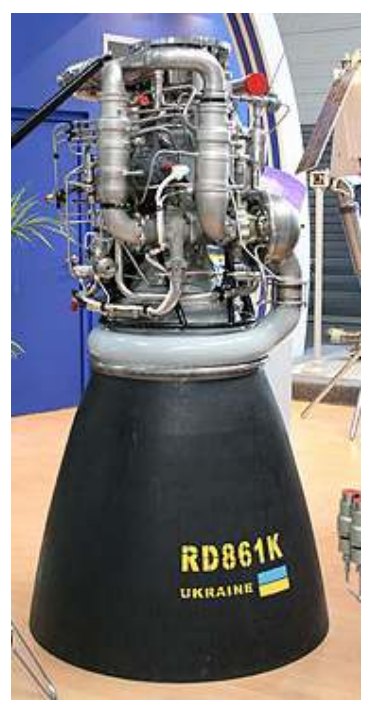

Рисунок 2 - Двигун РД861К

Управління вектором тяги здійснюється за рахунок повороту камери згорання на карданному підвісі, а відпрацьований турбінний газ подається в надзвукову частину сопла. Оскільки температура цього газу значно менша від температури продуктів горіння з основної камери, то насадок в місці вдуву навантажений меншими тепловими потоками.

Проведемо аналіз ефективності різних схем вихлопу відпрацьованого на турбіні генераторного газу. Розглянемо 4 схеми: а) вдув газу в закритичну частину сопла основної камери; б) вихлоп через окреме сопло; в) допалювання в спеціальній камері згорання в дефлаграційному режимі); г) допалювання в спеціальній камері згорання в детонаційному режимі;

Вихідними даними для оцінки є наступні параметри двигуна:

Питома тяга камери згорання

Тяга

Тиск на зрізі сопла

Тиск газу за турбіною

Показник адіабати

Газова стала продуктів горіння
$335,5 \mathrm{c}$ 7916 кгс $0,03 \mathrm{\kappa rc} / \mathrm{cm}^{2}$ $1,8 \mathrm{K \Gamma \textrm {C }} / \mathrm{cM}^{2}$ 1,2

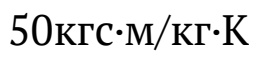


«Системні технології» 4 (129) 2020 «System technologies»

Теоретичний газодинамічний радіус зрізу насадку $\quad$ 493,1мм

Радіус зрізу насадку сопла $\quad$ 501,9мм

Додаткова тяга вихлопних пристроїв визначається за формулою [4]:

$$
F=U_{a} \cdot \dot{m}+S_{a} \cdot p_{a}
$$

В свою чергу Uа визначиться за формулою [4]:

$$
U_{a}=\sqrt{2 \cdot \frac{\gamma}{\gamma-1} \cdot R \cdot T \cdot\left[1-\left(\frac{p_{a}}{p_{2}}\right)^{\frac{\gamma-1}{\gamma}}\right]}
$$

де $\mathrm{U}_{\mathrm{a}}$ - швидкість виходу газів із сопла ;

$\dot{m}$ - витрата газу;

$\gamma$ - показник адіабати;

$\mathrm{Sa}$ - площа зрізу сопла

$\mathrm{R}$ - постійна газова стала для продуктів горіння в газогенераторі;

Т - температура газу;

$\mathrm{p}_{\mathrm{a}}$ - тиск на зрізі сопла;

$\mathrm{p}_{2}$ - тиск газу за турбіною;

Очевидно, що при низьких значеннях тиску в камері згорання допалювача неможливо отримати високі значення питомої тяги. Тому значення її приросту при вихлопі генераторного газу через окреме сопло та при допалюванні в дефлаграційному режимі

Оцінити приріст тяги за рахунок допалювання в детонаційному режимі досить важко, оскільки в реакцію вступають не вихідні компоненти палива а суміш газів, що ускладнює задачу. Окрім того для вихідних компонентів в літературі немає інформації з приводу параметрів їх детонації. Доказом можливості протікання цього процесу може свідчити той факт, що суміші несиметричного диметилгідразину з повітрям чи киснем детонують[5]. Інформації про можливість детонації горючих газів з тетроксидом азоту також немає, однак закис азоту N2O при деяких умовах детонує навіть без додавання пального.

Тому для оцінки використаємо значення перепаду тиску на ударній хвилі для сумішей несиметричного диметилгідразину з повітрям, а 
«Системні технології» 4 (129) 2020 «System technologies»

інші термодинамічні параметри будемо брати виходячи з реакції суміші газів після газогенератора з азотним тетроксидом при цьому тиску. Стехіометрична суміш газоподібного несиметричного диметилгідразину 3 повітрям характеризується наступними параметрами газової детонації [5]:

Швидкість детонаційної хвилі

$$
\begin{aligned}
& \mathrm{D}=1860 \mathrm{M} / \mathrm{c} \\
& \mathrm{M} 0=5,6 \\
& \Delta \mathrm{p}=20,1 \\
& 1,175
\end{aligned}
$$

Число Маха

Перепад тиску

Рівноважний показник адіабати

Тиск в зоні реакції :

$\mathrm{p}_{\text {д }}=\Delta \mathrm{p} \cdot \mathrm{p}_{2}=36,18 \mathrm{\kappa rc} / \mathrm{cm}^{2}$

Термодинамічні параметри суміші продуктів горіння після турбіни з азотним тетроксидом при цій умові наступні:

Температура в опалювачі

Коефіцієнт адіабати

Середня молекулярна маса

Газова постійна

$$
\begin{aligned}
& \text { Тдет =3161K; } \\
& \gamma=1,215 ; \\
& \mu c e p=24,24 \Gamma / \text { моль; } \\
& \mathrm{R}=34,98 \text { кгс·м/кг·K; }
\end{aligned}
$$

Значення основних параметрів двигуна з використанням того чи іншого способу вихлопу відпрацьованого на турбіні генераторного газу наведено в таблиці 2. Для прийняття рішення важливим фактором $\epsilon$ i масова досконалість конструкції [2]. 3 огляду на те, що варіанти 3 допалюванням генераторного газу в дефлаграційному режимі та вихлоп в окреме сопло поступаються існуючому варіанту, то для порівняння по критерію енергомасової ефективності в подальшому не враховуватимемо.

Конструктивно допалювач рис.3 складається 3 колектора подачі генераторного газу (1), який розподіляє його по кільцевій форсуночній головці (2). 
«Системні технології» 4 (129) 2020 «System technologies»

Таблиця 2

Параметри двигуна з різними варіантами вихлопу відпрацьованого на турбіні генераторного газу

\begin{tabular}{|l|l|l|l|}
\hline \multicolumn{1}{|c|}{ Параметр } & $\begin{array}{c}\text { Вихлоп через } \\
\text { окреме сопло }\end{array}$ & $\begin{array}{c}\text { Допалювання в } \\
\text { дефлаграційному } \\
\text { режимі }\end{array}$ & $\begin{array}{c}\text { Допалювання в } \\
\text { детонаційному } \\
\text { режимі }\end{array}$ \\
\hline Приріст тяги кгс & +7 & $+516,5$ & $+599,2$ \\
\hline Приріст тяги \% & $+0,088$ & $+6,52$ & $+7,6$ \\
\hline Приріст питомої тяги с & $-3,8$ & -1 & $+2,2$ \\
\hline Приріст питомої тяги \% & $-1,2$ & $-0,3$ & $+0,7$ \\
\hline
\end{tabular}

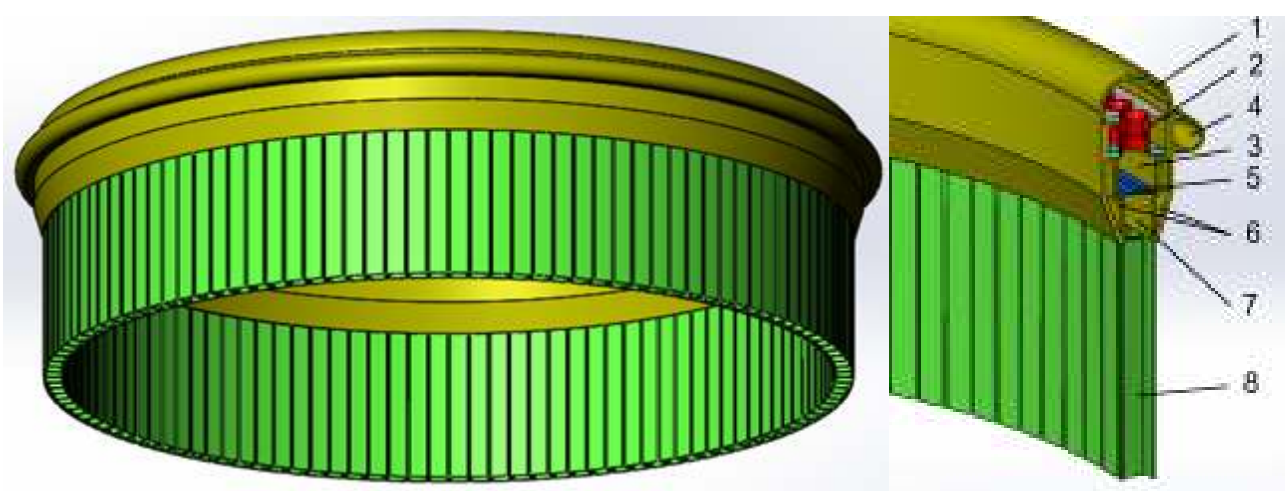

Рисунок 3 - Схема детонаційного допалювача генераторного турбінного газу

За нею розміщено форкамеру (3), в якій відбувається змішування рідкого окислювача, що поступає по магістралі (4) від турбонасосного агрегату, з «солодким газом». Для запобігання дії детонаційного фронту на елементи системи подачі форкамера відділена засобами нерозповсюдження детонаційного фронту (5). Конструктивно вони являють собою перфоровану пластину або сітку з матеріалу, що може витримувати екстремальні навантаження та температури. Для охолодження стінки допалювача (6) виконано пустотілими, куди потрапляє рідкий окислювач перед подачею в кільцеву форсуночну головку. Після утворення суміш поступає в детонаційну камеру згорання (7), що являє собою канал, в якому ініціюється ротаційна детонація. Камера з'єднана з детонаційними імпульсними трубками (8). Суміш заповнює канал та імпульсні трубки. Після ініціації детонаційна хвиля проходить в азимутальному напрямі по ка- 
«Системні технології» 4 (129) 2020 «System technologies»

налу і також розповсюджується вниз за течією газу по імпульсних трубках 3 надзвуковою швидкістю. Потік виходить в сопловий насадок двигуна в тому ж місці, де в штатного відбувається вдув відпрацьованого турбінного газу, тобто не потрібно змінювати конструкцію основної камери для інтеграції детонаційного допалювача.

Додаткова маса корисного вантажу, що може бути виведена на орбіту визначалась виходячи з характеристичної швидкості, що може бути отримана при наявних запасах палива та масі конструкції штатного варіанту. При цьому враховувалась додаткова маса детонаційного допалювача, що була визначена 3 комп’ютерного моделювання та становить 12,5кг. Маса додаткового корисного вантажу становить 35кг.

Висновок. Визначено приріст тяги і питомої тяги від вихлопу відпрацьованого генераторного газу для двигуна РД861К. Визначено також приріст від допалювання генераторного турбінного газу для двох режимів - дефлаграційного та детонаційного. Виявлено, що при вихлопі відпрацьованого генераторного газу через окреме сопло будуть значні втрати питомої тяги. При допалюванні відпрацьованого генераторного газу в дефлаграційному режимі також будуть втрати питомої тяги, однак менші ніж в попередньому варіанті. Це обумовлено низьким тиском після турбіни, що не дозволяє ефективно спалювати газ в допалювачі. Виявлено, що при допалюванні відпрацьованого генераторного газу в детонаційному режимі буде підвищення і тяги і питомої тяги. Оцінка проводилися наближено у зв’язку з відсутністю інформації та методики розрахунку детонації багатокомпонентних гетерогенних сумішей.

\section{ЛІТЕРАТУРА / ЛИТЕРАТУРА}

1. Двигатели 1944-2000 гг.: Авиационные, ракетные, морские, промышленные: Иллюстрированный справочник (сост. Шустов И.Г.) Серия: Отечественная авиационная и ракетно-космическая техника.

2. Конструкция и проектирование жидкостных ракетних двигателей / под ред. Г. Г. Гахуна. - М.: Машиностроение, 1989. - 424 с.

3. «Циклон-4» Ескізний проект / ДП «КБ Південне».

4. Алемасов В.Е. Теория ракетных двигателей / В.Е. Алемасов, А.Ф. Дрегалин, А. П. Тишин - М.: «Машиностроение», 1969. - 547с. 
«Системні технології» 4 (129) 2020 «System technologies»

5. Васильев А. А, Характеристики горения и детонации гидразина и его метилпроизводных / А. А Васильев, А. И. Валишев, В. А. Васильев, Л. В. Панфилова // Физика горения и взрыва, 2000, т. 36, ॰3 - С.81-96.

6. Детонаційний рідинний ракетний двигун / С. С.Василів, О.Є. Золотько, М.Д. Коваленко //Патент на винахід, №115370 Україна, MПК F02K9/42; заявник і патентоволодар Інститут технічної механіки НАНУ і ДКАУ.- заявлено 04.01. 2016р. опубл. 25.10.2017, Бюл.№20-4ст.

\section{REFERENCES}

1. Engines 1944-2000: Aircraft, rocket, marine, industrial: Illustrated reference book (compiled by I. Shustov) Series: Aviation and space-rocket technology.

2. Design and engineering of liquid rocket engines / ed. G. G. Gahuna. - M.: Mechanical Engineering, 1989 .- 424 p.

3. "Cyclone-4" One-sided project / DP "KB Pivdenne”.

4. Alemasov V.E. Theory of rocket engines / V.E. Alemasov, A.F. Dregalin, A.P. Tishin - M.: Mechanical Engineering, 1969. - 547 p.

5. Vasiliev A.A, Characteristics of combustion and detonation of hydrazine and its methyl derivatives / A.A Vasiliev, A.I. Valishev, V.A. Vasiliev, L.V. Panfilova // Combustion and Explosion Physics, 2000,v.36, N॰3 - P.81-96. 6. Detonation missile rocket engine / S.S. Vasiliv, O.€. Zolotko, M.D. Kovalenko // Patent № 115370 Ukraine, IPC F02K9 / 42; Applicant I Patentovolodar Institute of Technical Mechanics of NASU Д DKAU, publ. 10.25.2017. Bull. No. 20 - 4p.

Received 17.02.2020.

Accepted 21.02.2020.

Использование детонационного процесса для повышения энергетических характеристик ракетных двигателей верхних ступеней, построенных по открытой схеме

Статья посвящена анализу эффективности использования отработанного на турбине генераторного газа в двигателях верхних ступеней, построенных по открытой схеме, для выхлопа в отдельное сопло или дожигания его в дефлаграционном или детонационном режимах. Определены основные параметры двигательных установок с использованием этих устройств по сравнению с существующим вариантом двигателя. Определено, что дожигание отработанного на турбине генераторного газа в детонационном режиме позволяет повысить энергетические характеристики ракетного двигателя, построенного по открытой схеме, и увеличить массу полезного груза, выводимого на орбиmy.

The detonation process use for increasing the energy characteristics of upper stage rocket engine constructed on an open circuit

The article is devoted to the analysis of the efficiency of turbine exhaust gas use in the upper rocket engines, which are built on an open circuit. The works over rocket engines, used deto16 
«Системні технології» 4 (129) 2020 «System technologies»

nation burning process in a chamber are conducted in the different countries foe a long time. The main reason for the search in this direction is the higher thermodynamic efficiency of detonation compared to deflagration. The prospect of withdrawal from the turbo-pump unit when using a simple displacement feed system is also attractive, as the detonation process can occur at relatively low pressure values of the fuel components.

The aim of paper is an assessment of efficiency added combustion of turbine exhaust gas in the additional combust chamber in different modes.

The variants of exhaust of the turbine generator gas into a separate nozzle, its afterburning in deflagration and detonation modes are considered. There have defined the basic parameters of the engine installations using these devices, in comparison with the existing engine variant. The increase in thrust and specific thrust from exhaust of generator gas for engine RD861K is determined. For this engine the thrust vector is controlled by rotating the combustion chamber on the cardan suspension, and the exhaust turbine gas is fed into the supersonic part of the nozzle. Since the temperature of this gas is much lower than the temperature of the combustion products from the main chamber, the nozzle at the injection site is loaded with less heat fluxes.

The increase from the afterburning of the generator turbine gas for two modes - deflagration and detonation is also determined. It is revealed that the exhaust of the generated generator gas through a separate nozzle causes significant losses of the specific thrust. The afterburning of the exhaust gas in the deflagration mode also lead to a loss of specific thrust, but less than in the previous version. This is due to the low pressure after the turbine, which does not allow efficient combustion of gas in the afterburner. The combustion of the exhaust gas produced on the turbine in a detonation mode has been found to increase the energy performance of the rocket engine built in an open circuit and increase the payload to be put into orbit.

Василив Степан Степанович - младший научный сотрудник, Институт технической механики НАНУ и ГКАУ.

Евсеенко Максим Владимирович - инженер 1 категории, Институт технической механики НАНУ и ГКАУ.

Василів Степан Степанович - молодший науковий співробітник Інституту технічної механіки НАН України і ДКА України, м. Дніпро.

Євсєєнко Максим Володимирович -інженер 1 категорії Інституту технічної механіки НАН України і ДКА України, м. Дніпро.

Vasiliv Stepan - Junior Researcher, Institute of Technical Mechanics of the National Academy of Sciences of Ukraine and State Space Agency of Ukraine. Evseenko Maksim - Engineer of 1-st category, Institute of Technical Mechanics of the National Academy of Sciences of Ukraine and State Space Agency of Ukraine. 